\section{MISLEADING ILLUSTRATION}

Sir, the article reporting the potential reduction in healing times for dental implants is illustrated with a picture of a patient who appears to be in significant pain (News BDJ 2011; 211: 8). I feel this is misleading as in my experience the placement of dental implants is, for most patients, an uncomfortable procedure. If any of my patients suffered the pain your pictures seems to suggest I hope they would be contacting me urgently as I view significant post placement pain as a serious complication suggesting there were other potential problems with the procedure.

J. Fraser

By email

DOI: 10.1038/sj.bdj.2011.688

\section{STORAGE MEDIA}

Sir, I read with great interest the article entitled Current developments in interim transport (storage) media in dentistry: an update by N. Malhotra which has been published in your esteemed journal (BDJ 2011; 211: 29-33). It was an informative review on different transport media used for avulsed teeth. Apart from the storage media presented in the review, I would like to append a few more transport media which have been tested for their efficiency.

(a) Contact lens solution: Different types of lens solutions like Bausch and Lomb (Renu), Ciba Vision (Titmus), Alcon (Opti-free) etc have been used with conflicting results. Studies have demonstrated that they were worse than saline, milk and Hank's Balanced Salt Solution. The presence of preservatives in their formula was found to be harmful to the cells. ${ }^{1,2}$

(b) Ricetral: An oral rehydrating solution consisting of glucose and vital salts, in concentrations conjectured to be adequate for cell metabolism. It was shown to be better than milk in preserving the vitality of the periodontal ligament cells. ${ }^{3}$

(c) Green tea extract: Has the efficiency of maintaining the vitality of periodontal ligament cells similar to that of HBSS and higher than milk. ${ }^{4}$ It has unprecedented anti-inflammatory, antioxygenic, antioxidant and anticarcinogenic properties which are related to the most abundant polyphenol Epigallocatechin-3-gallate (EGCG) present in it. These properties allow the successful preservations of tissues and cells.

\section{Ballal, Jothi V.} Manipal

1. Huang S C, Remeikis N A, Daniel J C. Effects of long-term exposure of human periodontal ligament cells to milk and other solutions. J Endod 1996; 22: 30-33.

2. Chamorro M M, Regan J D, Opperman L A, Kramer PR. Effect of storage media on human periodontal ligament cell apoptosis. Dent Traumatol 2008; 24: 11-16.

3. Rajendran P, Nettiyat O V, Varughese J M, Murugaian E. Evaluation, using extracted human teeth, of Ricetral as a storage medium for avulsions - an in vitro study. Dent Traumatol 2011; 27: 217-220.

4. Jung I H, Yun J H, Ch A R, Kim C S, Chung W G, Choi S H. Effect of (-)-epigallocatechin-3-gallate on maintaining the periodontal ligament cell viability of avulsed teeth: a preliminary study. J Periodontal Implant Sci 2011; 41: 10-16.

DOI: 10.1038/sj.bdj.2011.689

\section{HEARTFELT THANKS}

Sir, in November 2010, you published my letter on behalf of the charity Christian Relief Uganda (CRU), appealing for dental textbooks for students of Malago Dental School in Uganda.

There was a generous response from readers enabling a comprehensive collection over 100 books to be taken out by CRU in May, and the following letter has been received by the charity from one of the recipient dental students:

Christian greetings from Kampala, Uganda.

I write to acknowledge receipt of the consignment of books that you collected and sent through Barbara Koffman of CRU to Uganda.

On my own behalf and the entire Ugandan team, I would like to extend our heartfelt thanks to you and every body in UK who has contributed to the wealth of knowledge that you have built up in Uganda.

It is worth noting that dental profession is relatively young, tracing commencement of its training to 1970s for Diploma and BDS in late 1980s. For this reason and a number of other bottlenecks, oral health literature for students, lecturers and researchers is still scanty.

We therefore thank you for your kind generosity to send very good oral health books.

We pledge to put them to good use and this shall be manifested through regular reference for study purposes.

Many thanks once again!

Kind regards,

Ambrose Matsika

Further supplies of textbooks/DVDs can be taken out on future CRU missions. Laptops and mobile phones with cameras would also be of great use to the students.

Please contact Barbara Koffman at bkoffmancru@hotmail.co.uk if you can help in any way. Thank you.

R. Longhurst Exmouth DOI: $10.1038 /$ sj.bdj.2011.690

\section{EVIDENCED BY EXPERIENCE}

Sir, I write regarding the evidence summary Which dental liners under amalgam restorations are more effective in reducing postoperative sensitivity? (BDJ 2011; 210: 533-537). Amalgam as far as the conductivity of thermal changes are concerned acts like a metal whereas enamel and dentine are poor conductors.

Amalgam cavities should be lined with a quick setting zinc oxide/oil of cloves material such as SEDANOL. This lining is bacteriostatic, non-irritant and well able to withstand, unlike DYCAL, the condensation pressure of packing the amalgam.

Amalgam is also the only filling material that advantageously expands when it sets. A little application of Duraphat varnish to the perimeters of the cavity prior to inserting the amalgam will leave it with an effective seal.

This statement is 'evidence-based' since I used it successfully for over 50 years.

A. E. Castle Drayton DOI: 10.1038/sj.bdj.2011.691 